\title{
Corrosion Behavior of Welded Repaires for Water Turbine Blades
}

\author{
ROBERT CIOCOIU ${ }^{1}$, RAZVAN COMAN ${ }^{1}$, OCTAVIAN TRANTE $^{1 *}$, ANCA DANIELA RAICIU2*, MIHAI VASILE ${ }^{1}$, ION CIUCA ${ }^{1}$, \\ NICOLAE NAVODARIU ${ }^{1}$, IOAN CRISTESCU ${ }^{1}$ \\ 'University Politehnica of Bucharest, 313 Splaiul Independentei Str., 060042, Bucharest, Romania \\ 2 Titu Maiorescu University, Faculty of Pharmacy, Department of Pharmacognosy Phytochem Phytoterapy, 16 Gheorghe Sincai \\ Str., 040317, Bucharest, Romania
}

The immersed components of hydroelectric power plants are permanently in contact with the water stream and their wear occurs by corrosion, erosion and cavitation. This damage is usually repaired by welding: the procedure is fast and reduces plant downtime. Adopting proper weld procedures are crucial for blade performance and to establish a protocol the following experiment was devised: rectangular samples $600 \times 200 \times 15 \mathrm{~mm}$ were obtained from a discarded blade used in a hydroelectric power plant and in the median region a $3 \mathrm{~mm}$ deep groove was milled to simulate erosion damage. The damage was repaired by welding using MIG, WIG, MMAW and oxyacetylene techniques using $136 \mathrm{~L}$ as filler on cold and preheated at 400U C base materials. Specimens from the welded ensembles were obtained and prepared accordingly for corrosion testing. Post corrosion testing studies using the lightmicroscope and scanning electron microscope were performed in order to determine surface damage. At first glance results appear contradictory: the corrosion test results revealed best behavior for MIG weld repairs, on the cold sample, while the corrosion features measured on the exposed area revealed that oxyacetylene welding would be best. Complementary methods are required and currently employed to establish optimum welding procedure parameters for water turbine blade repairs.

Keywords: water turbine blade, weld repair, corrosion behavior.

Underwater turbine components (blades, runners, vanes) are subjected to high energy water jet and wear occurs by corrosion, erosion and cavitation. Erosion is similar to the metal cutting process due to mineral particles present in water, while cavitation can be regarded as a form of surface fatigue caused by high energy water droplets impingement [1-3]. Cavitation alone can create pits up to $10 \mathrm{~mm} /$ year in depth, causing material loss of even $5 \mathrm{~kg} / \mathrm{m}^{2} / 10000 \mathrm{~h}$ [4].

Corrosion means metal deterioration or surface damage in an aggressive environment, a chemical or electrochemical process of electron transfer towards the environment.

Proper materials for underwater turbine parts are of high importance [5], along proper mechanical characteristics they should be erosion resistant and own good weldability for onsite repairs: stainless steels such as 13Cr1Ni and AISI 410 have been used with satisfactory results.

In industry codes and standards are presented for base and filler metals and, although these requirements are met, there are times when the welded region behaves in an unpredictable manner.

In welded repairs the corrosion resistance is influenced by welding practice and sequence, possible contamination, incomplete fusion, porosities, cracks, stresses and surface finish. From a metallurgical view point the main factors for corrosion resistance are micro segregations, phase precipitations, recrystallization and grain growth, loss of alloying elements and contamination of the weld pool [6].

Welded regions are prone to all classical forms of corrosion and especially susceptible to those influenced by microstructure and composition variation: galvanic couples, pitting, stress corrosion and intergranular corrosion [7].

The aim of this study was to investigate the weldrepaired regions corrosion behavior to find the most effective method for repairing the erosion damaged areas and ensure best performance for the turbine blade.

\section{Experimental part}

\section{Materials and methods}

The tests were performed on samples obtained from a discarded hydroelectric power plant turbine blade. First analysis was to determine the chemical composition of the base material using a SPECTROMAXX optical emission spectrometer.

Further nine samples $600 \times 15 \times 15 \mathrm{~mm}$ were obtained by cutting and milling. In eight samples a $3 \mathrm{~mm}$ deep groove was milled to simulate erosion damage and then filled by welding using following techniques: metals inert gas welding (MIG), wolfram inert gas welding (WIG), manual metal arc welding (MMAW) and an oxyacetylene welding following a procedure similar to an in-situ repair. The filler material was chosen as 316L stainless steel. The schematic presented in figure 1.a shows the rectangular steel sample
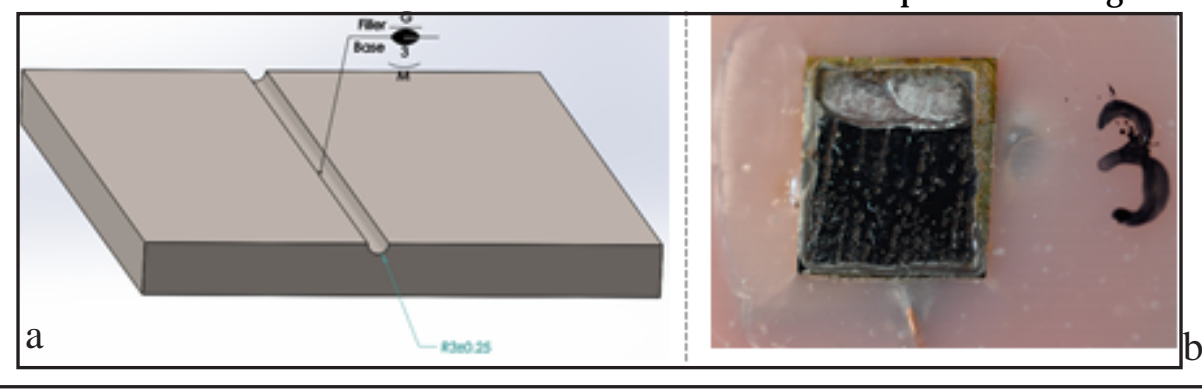

Fig. 1 Sample processing showing the a. schematic depicting machined groove for weld repair and b. mounted sample post corrosion testing

*email: tranteoctavian@yahoo.com; daniela_raiciu@yahoo.com All authors have participated equally in developing this study 
Table 1

SAMPLE CODING AND PROCESSING

\begin{tabular}{|c|c|c|}
\hline Sample & Welding method & Preheating \\
\hline P0 & Not welded (reference) & No \\
\hline P1 & MMAW & No \\
\hline P2 & WMAW & $400^{\circ} \mathrm{C}$ \\
\hline P3 & WIG & No \\
\hline P4 & Oxyacetylene welding & No \\
\hline P5 & Oxyacetylene welding & $400^{\circ} \mathrm{C}$ \\
\hline P6 & MIG & No \\
\hline P7 & MIG & $400^{\circ} \mathrm{C}$ \\
\hline P8 & & \\
\hline
\end{tabular}

with the $3 \mathrm{~mm}$ deep groove milled and prepared for welding. In mostinternal maintenance procedures for water turbine blade repairs $3 \mathrm{~mm}$ deep and above erosion features are mandatory for repair and weld surface finish performed by grinding.

A set of samples was preheated at $400^{\circ} \mathrm{C}$ another welded at ordinary temperature and a sample was used as reference. Sample coding and processing is resumed in table 1.

From the large ensembles samples for corrosion testing samples were selected to include: weld material, base material and a portion of the heat affected zone (HAZ) as shown in figure 1.b, prepared according to ASTM G5 and tested using a Potentiostat/Galvanostat PARSTAT 400.

Post corrosion testing was performed using an Olympus SZX7 stereomicroscope, Reichert UnivaR optical microscope and a Quanta Inspect F50 scanning electron microscope equipped with energy-dispersive X-ray spectrometer (EDS).

\section{Results and discussions}

The chemical composition of the steel is shown in table 2 approximates that of AISI 414 (UNS S41400) stainless steel, but component concentration variation led us to the conclusion that it is 10Ch12NDL casting stainless steel according to GOST 977 /988 composition for specific use in hydroelectric power plants given its higher copper content introduced for higher mechanical characteristics $[8,9]$.

The chromium $\left(\mathrm{Cr}_{\mathrm{eg}}\right)$ and nickel $\left(\llbracket N i \rrbracket_{\downarrow} e q\right)$ equivalents were determined for the Schaeffler constitution diagrams [10] using equations (1) and (2) in which the weight percentage of specified alloying elements are used.

$$
\begin{aligned}
& C r_{e q}=\% C r+\% M o+1.5 \cdot \% S i+0.5 \cdot \% N b \\
& N i_{e q}=\% N i+30 \cdot \% C+0.5 \cdot \% M n
\end{aligned}
$$

The values of $\mathrm{Cr}_{\mathrm{eg}}=13.50$ and $\mathrm{Ni}=2.76$ on the Schaeffler diagram predict a structure composed of two phases, martensite and ferrite.

The corrosion tests were performed according to ASTM G5, the samples had a $10 \times 10 \mathrm{~mm}$ exposed surface, prepared as specified. The tests were performed in $3.5 \% \mathrm{NaCl}$ solution at $25^{\circ} \mathrm{C}$ for $3 \mathrm{~h}$. The Potential vs. Elapsed
Table 2

CHEMICAL COMPOSITION OF THE STEEL USED AS BASE MATERIAL

\begin{tabular}{|c|c|c|c|c|c|c|}
\hline $\mathrm{C}$ & $\mathrm{Si}$ & $\mathrm{Mn}$ & $\mathrm{Cr}$ & $\mathrm{Ni}$ & $\mathrm{Cu}$ & $\mathrm{Fe}$ \\
\hline 0.037 & 0.275 & 0.491 & 13.01 & 1.40 & 1.30 & Balance \\
\hline
\end{tabular}

time and Current Density vs. Potential are shown in figure 2 and 3 .

The fluctuations in electrode activity observable in figure 2 suggest passive film breakdown or repair and the slow potential rise followed by steep decay is the typical behavior of pitting corrosion [11, 12], as seen in figure 2 .

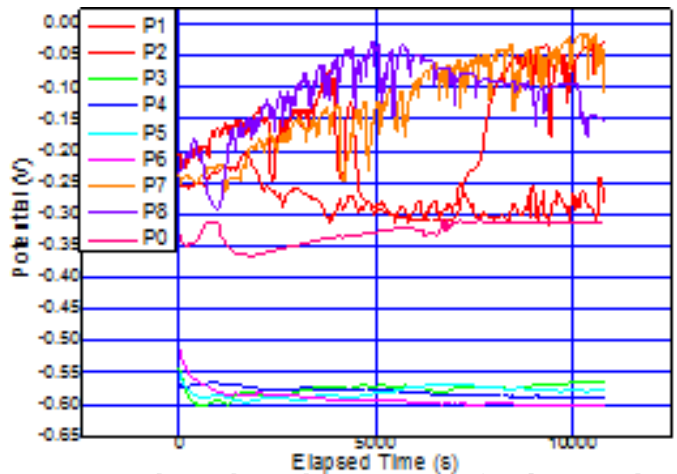

Fig. 2 Potential vs. Elapsed time curves for the tested samples

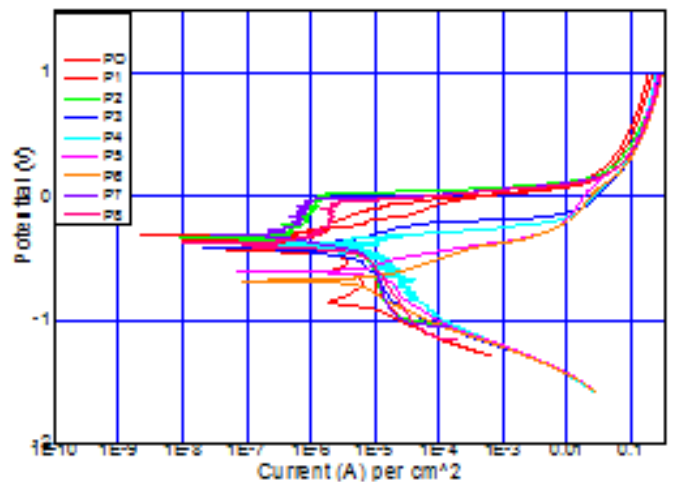

Fig. 3 Potential vs. Current density curves for the tested samples

Using open circuit potential $\left(E_{a c}\right)$ as criterion the most positive values reveal better corrosion behavior [13], in this case P2, P7, P8 and P1 exhibited the best behavior as observed according to the variation presented in figure 4.

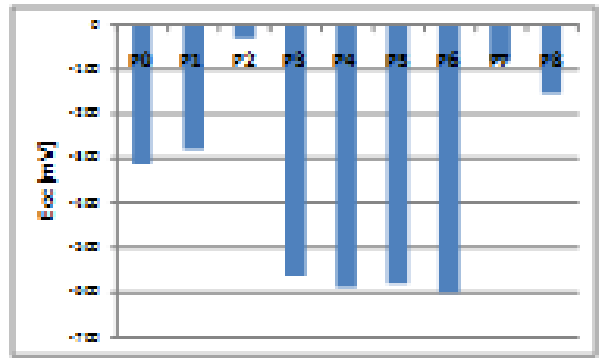

Fig. 4 Comparison of open circuit potential for tested samples

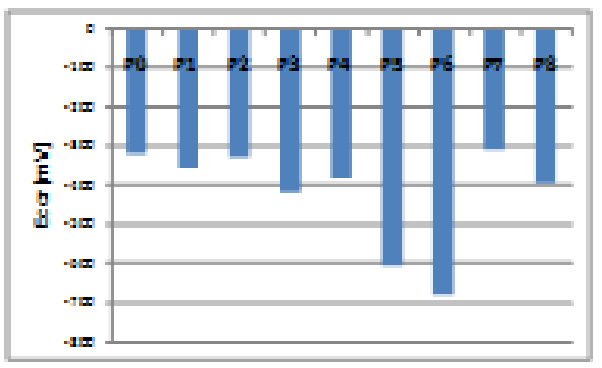

Fig. 5 Comparison of corrosion potential for tested samples. 


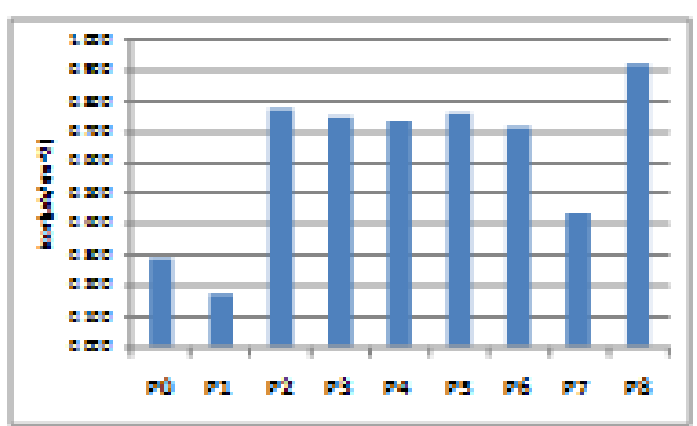

Fig. 6 Comparison of corrosion current density for tested samples.

Using the corrosion potential $\left(E_{\text {crt }}\right)$ as criterion the more electro-positive values suggest better corrosion behavior [14], from figure 5 sample P7 would be most corrosion resistant, followed by P2, P1, P4 and P8.

Lower values of corrosion current density $\left(I_{\text {cor }}\right)$ suggest good corrosion resistance [15], the variation presented in figure 6 suggests sample P1 to be best, followed by $\mathrm{P} 7$ and P3.

Considering all criteria, sample $\mathrm{P} 7$ has the best corrosion resistance while samples $\mathrm{P} 5$ and $\mathrm{P} 6$ showed poor corrosion behavior. Sample P5 is the least corrosion resistant.

Post corrosion testing the samples are studied using the Olympus SZX7 stereo-microscope was used to study the sample surface. In figure 7 surface aspects of corroded samples are shown: figure $7 \mathrm{a}$ the reference sample $\mathrm{PO}$, figure 7.b the sample with best corrosion resistance, P7 and figure 7c worst corrosion behavior sample P5.

Aspects of pitting corrosion can be observed in figure 7.a and 7.b, while in the case of sample P5, figure 7.c, the features tend to extend towards a generalized corrosion. An interesting feature can be observed in figure 7.c: little corrosion features appear in the heat affected zone and in sample P7, figure 7.C, the pits have a radial orientation.
By macroscopic observation alone it would be tempting to appreciate that sample P5 showed the best corrosion resistance and $\mathrm{P} 7$ the worst, the opposite of the corrosion tests results.

Further studies on the corroded test samples implied a qualitative analysis using the area with corrosion features using the Reichert optical microscope and the dedicated software. A total of 5 fields of interest were captured and the corrosion damaged area determined, results are shown in fig. 8 using the same sample succession as presented in the stereomicroscopy studies.

For comparison a bar chart showing the percentage of corroded surface area is constructed shown in figure 9.

Using corroded surface area as criterion for corrosion resistance the worst behavior is shown by sample $\mathrm{P} 7$ followed by $P 8$ and the best behavior was estimated at P5, $\mathrm{P} 1, \mathrm{P} 3$ and $\mathrm{P} 2$.

The results are contradictory at this stage and further studies were required to explain the behavior. Using the scanning electron microscope equipped with EDS the corroded samples were studied to determine corrosion aspectmorphology, distribution and chemical composition and element distribution.

In the reference sample P1, figure 10a, the pits have a slightly elliptical appearance and are either shallow either deep, while sample P5 which showed worst corrosion behavior revealed shallow pits shown in figure 10b. Sample P7 showed most damage with pits distributed in a radial manner starting from the welding electrode, as seen in fig. $10 \mathrm{c}$. The depth of the corrosion features was appreciated as lowest for sample P7.

To study alloying element distribution in the regions of interest elemental distribution maps obtained by EDS was the method employed. Regions of interest were selected and important alloying element such as $\mathrm{Cr}, \mathrm{Ni}, \mathrm{Mn}, \mathrm{Cu}$ distribution studied.
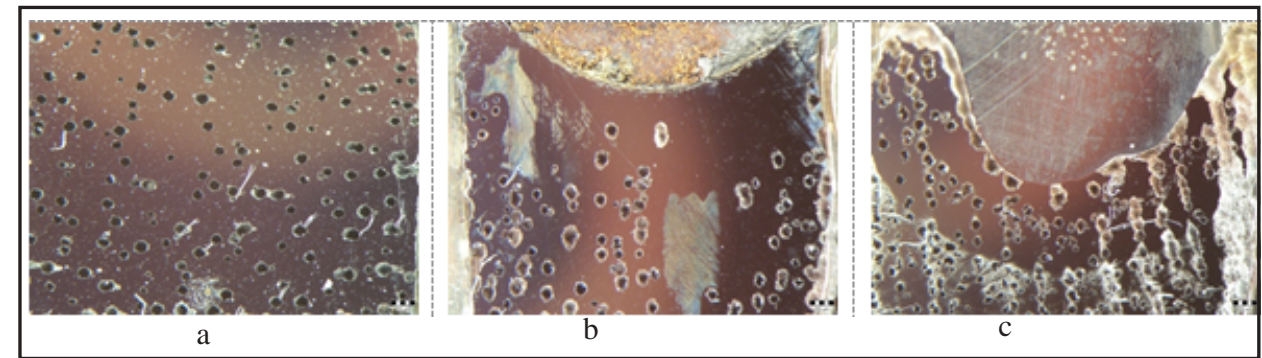

Fig. 7 Corrosion aspects on sample a. P0, b. P5 and c. P7. Magnification: 20X
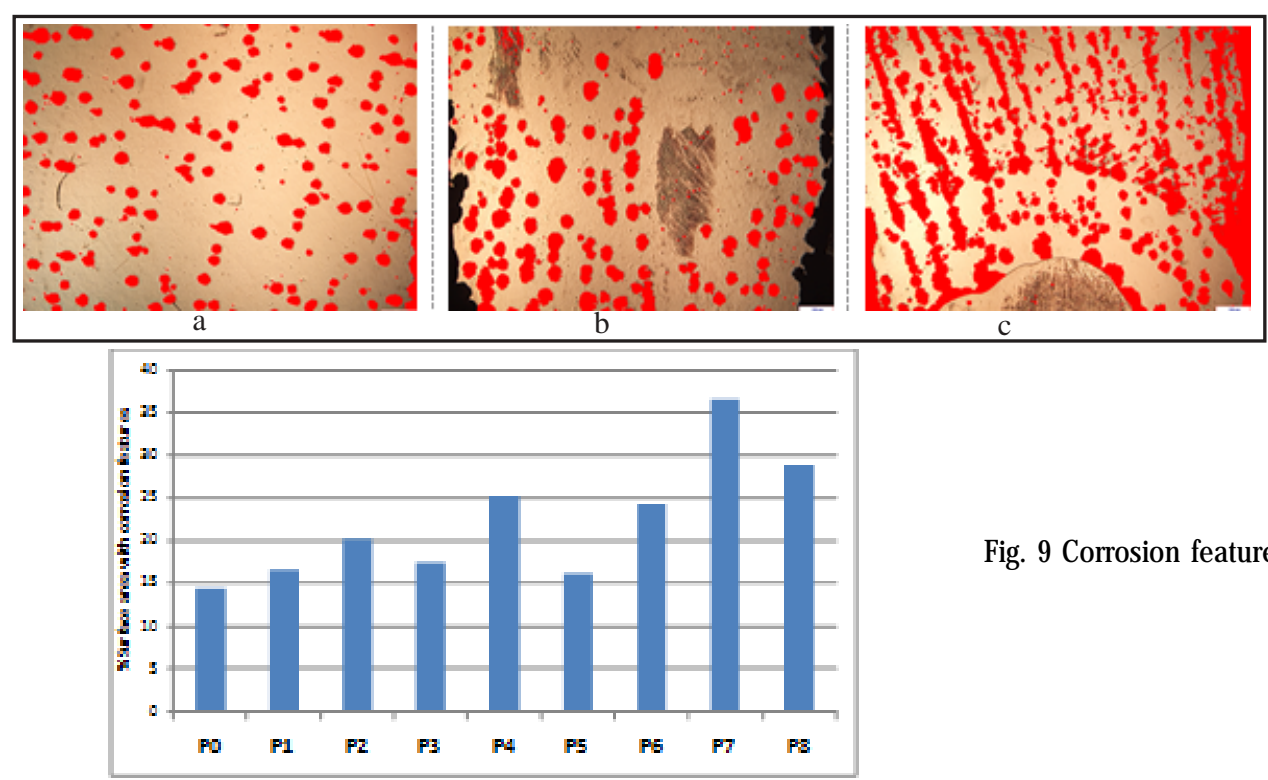

Fig. 8 Processed images for corrosion aspects on sample a. P0, b. P5 and C. P7.

Fig. 9 Corrosion features on the investigated surfaces 


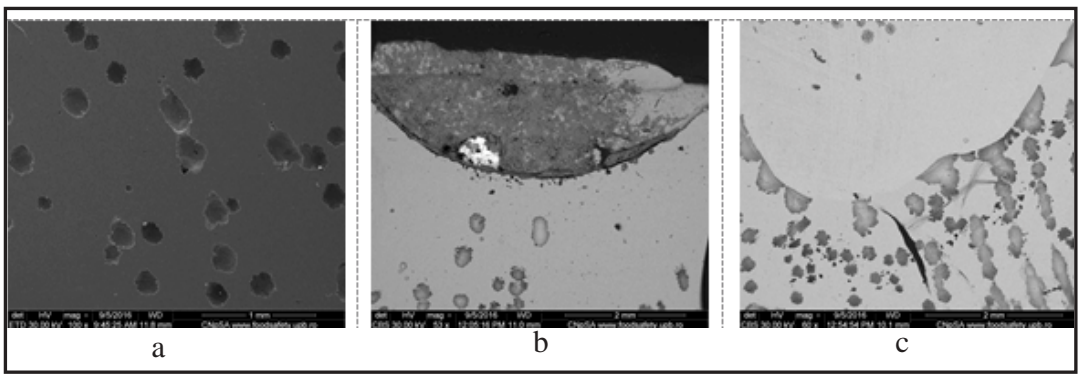

Fig. 10 Scanning electron microscopy images showing pit morphology and distribution in a. reference sample $\mathrm{P} 0$, b. sample $\mathrm{P} 5$ and $\mathrm{c}$. sample P7

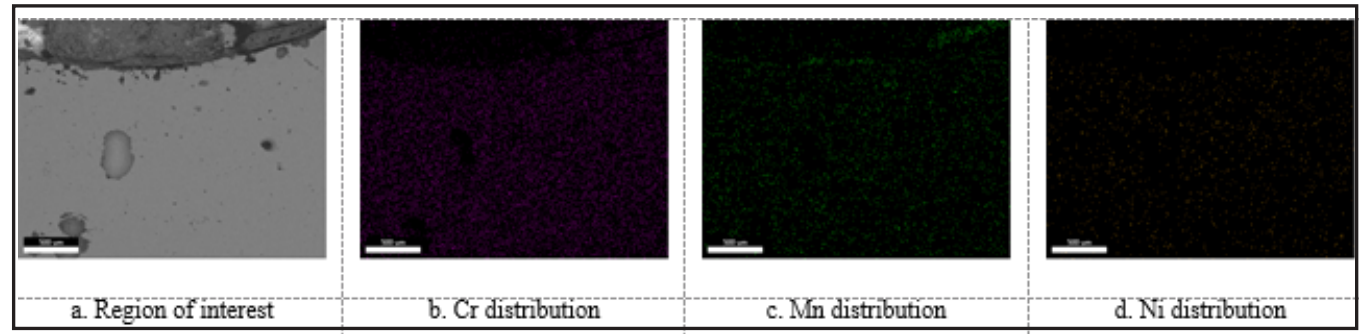

Fig. 11 Elemental distribution in sample P5
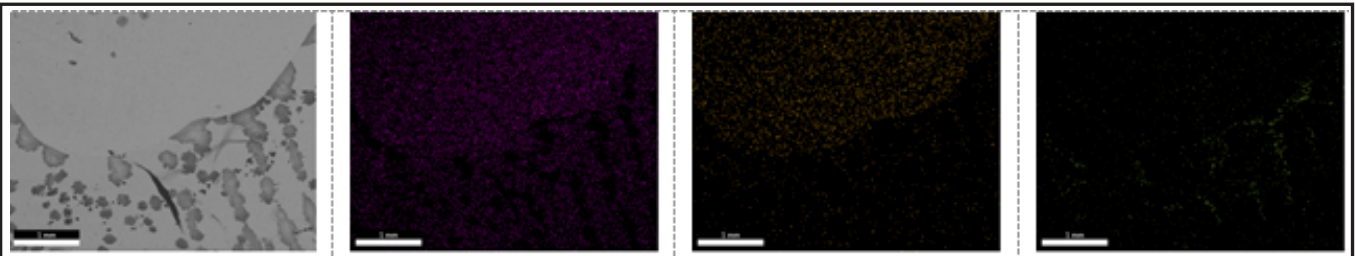

Fig. 12 Elemental distribution in sample P7

a. Region of interest b. Cr distribution c. Ni distribution d. Cu distribution

In figure 1la the region of interest is shown which comprises the weld material, heat affected zone and base material and in figure $11 \mathrm{~b}$ to $\mathrm{d} \mathrm{Cr}, \mathrm{Mn}$ and $\mathrm{Ni}$ distributions.

According to the element distribution the weld material appears to be depleted in $\mathrm{Cr}$ and $\mathrm{Ni}$ or a thick oxide film was formed either during corrosion test. Regions with high Mn contents appear at the weld material - base material interface, where MnS could have formed.

In a similar manner, in figure 12 the elemental maps obtained on sample P7 are shown for $\mathrm{Cr}$, Ni and $\mathrm{Cu}$.

In figure 12. $\mathrm{b}$ and $\mathrm{C} \mathrm{Cr}$ and $\mathrm{Ni}$ appear in higher concentrations in the weld material, while in the base material copper rich regions are present, a segregation occurred most likely in the melted material.

Dissimilar chemical composition of the filler and base material is the main reason element distribution: diffusion and segregation are possible in the welded and nearby regions.

In duplex stainless steels Yan [16] states that the pitting corrosion resistance decreases from base material to weld material and heat affected zone, while $\mathrm{Ma}$ [17] states that in case of austenitic stainless steels the heat affected zone shows lowest corrosion resistance.

The dissimilar nature of the alloys used for this study and the various methods used made such classification impossible: in some cases the filler material was strongly corroded while in other little or no corrosion was observed. The behavior of the base material was mostly the same and for the heat affected zone either was strongly or mildly corroded. No clear pattern was distinguished.

\section{Conclusions}

Water turbine blade erosion damage are repaired by welding and the majority of repair procedures recommend filler materials and sometimes welding method to be employed. In this study four welding methods were employed, using the same filler material and using cold and preheated samples. Intentionally, welding patterns and parameters were not controlled to mimic an in-situ repair where the welder is confined by space.

Corrosion tests results suggested that MIG welding on cold samples should give best corrosion resistance while oxyacetylene welding worst results. Complementary, corroded surface studies suggest the contrary -it must be mentioned that surface features alone were studied, their depth was not included.

Sample preheating had little influence on the results.

The contradictory results can be explained from a metallurgical perspective: diffusion and depletion in chromium and nickel (alloying elements crucial for corrosion resistance in steels) of some regions, segregation and compound formation (oxides, $\mathrm{MnS}, \mathrm{Cr}_{23} \mathrm{C}_{6}$ ) and sensitizing create conditions for localized corrosion. Another factor of influence on the results is the precise proportion of filler material/base material included in the studied area - unfortunately uncontrollable in this experiment.

Current results recommend MIG welding for repairs, still further studies regarding welding parameters as heat source speed and temperature are ongoing.

\section{References}

1. KIROLS, H.S., KEVORKOV, D., UIHLEIN, A, MEDRAJ, M., Mater Res Express 2017;4

2. GHIBAN, B., BORDEASU, I., GHIBAN, N., BADARAU, R., HADAR, A., SERBAN, N., Annals of Daaam for $2008 \&$ Proceedings of the 19th International DAAAM Symposium, 2008:541-2

3. BORDEASU, I., GHIBAN, B., POPOVICIU, M.O., BALASOIU, V., BIRAU N., KARABENCIOV, A., Annals of Daaam for $2008 \&$ Proceedings of the 19th International DAAAM Symposium 2008:147-8

4. SIMONEAU, R., The optimum protection of hydraulic turbines against cavitation erosion.12th IAHR Symposium, Stirling, UK, Aug, 1984

5. SOHACIU, M., CIUCA, S., SAVASTRU, D., COMAN, G., PREDESCU, A., BERBECARU, A., et al., Optoelectron Adv Mat 2016;10:257-61

6. BHADURI, A.K., GILL, T.P.S., ALBERT, S.K., SHANMUGAM, K., IYER, D.R., Nucl Eng Des 2001;206:249-59 
7. PARDO, A., MERINO, M.C., COY, A.E., VIEJ O, F., ARRABAL, R., MATYKINA, E., Corros Sci 2008;50:1796-806.

8. ZIEWIEC, A., CZECH, J., TASAK, E., Arch Metall Mater 2012;57:105561

9. COMAN, G., CIUCA, S., BERBECARU, A.C., PANTILIMON, M.C., SOHACIU, M.G., GRADINARU, C., etal., Univ Politeh Buchar 2017;79:209218

10. LEE, S., LEE, C.Y., LEE, Y.K., J Alloy Compd 2015;628:46-9

11. GABRIELLI, C., HUET, F., KEDDAM, M., OLTRA, R., Rev. Coat. Corros. 3:229-267, 1981

12. JEGDIC, B., BOBIC, B., RADOJ KOVIC, B., ALIC. B., RADOVANOVIC,

L., J Mater Process Tech 2019;266:579-87
13. COTRUT, C.M., BRAIC, L., VRANCEANU, D.M., KISS, A., DINU, M., BALACEANU, M., et al., Mater Corros 2017;68:552-9

14. BRAIC, M., VLADESCU, A., BRAIC, V., COTRUT, C.M., STANCIU, D., Mater Corros 2015;66:1331-7

15.VOICULESCU, I., GEANTA, V., STEFANOIU, R., COTRUT, C., CIOCOIU, R., IONESCU M., Euroinvent Icir 2018 2018;374

16. YAN, H., XIN, S., YANG, Y., YANG, S., LI, M., Int J Electrochem Sc 2019;14:1423-33

17. MA, C., PENG, Q.J., MEI, J. N., HAN, E.H., KE W., J Mater Sci Technol 2018;34:1823-34

$\overline{\text { Manuscript received: } 15.09 .2018}$ 